\title{
openheart Impact of social deprivation on outcome following transcatheter aortic valve implantation (TAVI)
}

\author{
Kevin Mohee (D) , ${ }^{1}$ Majd B Protty (D) , ${ }^{2}$ Tony Whiffen, ${ }^{3}$ Alexander Chase, ${ }^{1}$ \\ Dave Smith ${ }^{1}$
}

To cite: Mohee K, Protty MB, Whiffen $\mathrm{T}$, et al. Impact of social deprivation on outcome following transcatheter aortic valve implantation (TAVI). Open Heart 2019;6:e001089. doi:10.1136/

openhrt-2019-001089

Received 13 May 2019

Revised 7 October 2019

Accepted 18 November 2019

Check for updates

(c) Author(s) (or their employer(s)) 2019. Re-use permitted under CC BY-NC. No commercial re-use. See rights and permissions. Published by BMJ.

'Department of Cardiology, Morriston Hospital, Swansea Bay University Health Board, Swansea, UK

${ }^{2}$ Systems Immunity University Research Institute, Cardiff University, Cardiff, UK

${ }^{3}$ Welsh Government, Cardiff, Administrative Data Research Unit, Cardiff, UK

Correspondence to Dr Kevin Mohee; kevin.mohee@ nhs.net

\section{ABSTRACT}

Objectives We sought to evaluate whether socioeconomic status influences outcome after first-time transcatheter aortic valve implantation (TAVI).

Method This is a single-centre study carried out in Swansea, South West Wales, UK between 5 November 2009 and 10 June 2018. Data included age, gender, domiciliary postal code, comorbidities, complications postTAVI, length of stay, follow-up time and survival status. The Welsh Index of Multiple Deprivation, 2014 was used to stratify cases by level of social deprivation according to domiciliary postal codes.

Results Study population was 387 patients of whom $213(54.8 \%)$ were men with mean age \pm SD of $82.8 \pm 8.3$ years. Patients, who were less deprived (296 (76.4\%)), were more likely to be older ( $83.5 \pm 7.9$ vs $80.4 \pm 9.3$, $\mathrm{p}<0.05)$ and to be married $(83.2 \%$ vs $69.7 \%, \mathrm{p}<0.05)$. Conversely, 'more deprived' patients $(91$ (23.6\%)) were more likely to have a longer stay in hospital as compared with patients in the 'less deprived group' $(29.6 \pm 32.7$ days vs $21.3 \pm 21.1$ days, $p<0.05)$. However, 30 -day, 1 -year and 3 -year survival/mortality rates were similar across all socioeconomic levels.

Conclusions This is the first study in which social deprivation has been investigated as a risk factor for mortality in a high-risk group of patients with severe aortic stenosis undergoing TAVI. Residing in a 'more deprived' area in South West Wales is not associated with adverse outcome following TAVI but patients who are 'more deprived' tend to stay longer in hospital compared with patients who are 'less deprived'.

\section{INTRODUCTION}

Aortic stenosis (AS) has become an increasingly more common global occurrence in increasingly elderly populations. ${ }^{1}$ Transcatheter aortic valve implantation (TAVI) is widely used for the treatment of severe symptomatic AS in patients who are deemed to be at high to intermediate high risk to undergo surgical aortic valve (AV) replacement, ${ }^{2}$ although recent evidence is emerging for its utility in low-risk populations as well. ${ }^{34}$ As a result, it is likely that volumes of TAVI procedures will increase significantly in the future.

\section{Key questions}

What is already known about this subject?

- Transcatheter aortic valve implantation (TAVI) is widely used for the treatment of severe symptomatic aortic stenosis in patients who are deemed to be at high to intermediate high risk to undergo surgical aortic valve replacement, although recent evidence is emerging for its utility in low-risk populations as well. As a result, it is likely that volumes of TAVI procedures will increase significantly in the future.

What does this study add?

- The interaction between outcomes following TAVI and socioeconomic status has received limited attention until now. This is the first study in which social deprivation has been investigated as a risk factor for mortality in a high-risk group of patients with severe aortic stenosis undergoing TAVI.

How might this impact on clinical practice?

- The findings of this study may, therefore, impact on procedural planning and discharge strategies given the association between socioeconomic deprivation and the increased prevalence of heart valve disease. Likewise, the increasing volume of TAVI implants that are likely to occur as a result of the recently published low-risk trials of TAVI versus conventional surgery.

The relationship between socioeconomic status and various components of health is well established. Studies have shown that residing in the most deprived areas in the UK contributes to a 3.5-fold greater risk for coronary heart disease (CHD) mortality than living in the least deprived areas ${ }^{56}$ and is associated with earlier development of CHD and greater prevalence of CHD-associated risk factors. ${ }^{7-9}$ The OxVALVE Population Cohort Study (OxVALVE) carried out in the UK found that the prevalence of undiagnosed CHD was higher in lower socioeconomic groups. $^{9}$

The interaction between outcomes following TAVI and socioeconomic status has received limited attention until now. The aim 
of this study is to investigate the relationship between socioeconomic factors and outcomes following TAVI using deprivation measures calculated on the basis of domicile postcodes, in an area of the UK with high levels of socioeconomic deprivation.

\section{METHODS}

\section{Setting and sample}

This retrospective case observational study identified 387 patients with severe AS (AV area $\leq 1 \mathrm{~cm}^{2}$ and/or AV area index $\leq 0.60 \mathrm{~cm}^{2} / \mathrm{m}^{2}$ and/or AV velocity $\geq 4 \mathrm{~m} / \mathrm{s}$ ) who underwent first-time TAVI between 5 November 2009 and 10 June 2018 at Morriston Cardiac Centre, Swansea. Patients undergoing 'valve-in-valve' TAVI for degenerate aortic bioprostheses were excluded. Demographic data were collected using electronic medical records. Domicile postal codes were recorded as part of demographic data. On the basis of these postal codes, patients were assigned a deprivation code using the Welsh Index of Multiple Deprivation, 2014 (WIMD).

The WIMD is the official measure of relative deprivation for small areas in Wales produced by the Welsh Government and was developed as a tool to identify and understand deprivation in Wales. Eight domains of deprivation are included: employment, income, education, health, community safety, geographical access to services, housing and physical environment. Each domain is made up of a number of indicators and there are 35 indicators in total that compromise the WIMD 2014.

The income domain indicator has the highest weighting (23\%) for the overall WIMD score and was used as a marker of deprivation in this study for a number of reasons. In contrast to the WIMD rank (which is based on a relative score), the income domain indicator is an absolute score, which provides the percentage of those living in the area receiving income-related benefits. It has an extremely high correlation with the overall deprivation index. ${ }^{10}$ Using the WIMD rank, each patient was assigned the corresponding income domain indicator score and this was used as an absolute measure of deprivation in the analysis. ${ }^{11}$ In order to analyse whether there were any differences in the patient demographics, injury mechanisms and outcomes, patients were classified as 'more deprived' if their income domain indicator score was $22 \%$ or more and 'less deprived' if their score was $21 \%$ or less. This cut-off value corresponds to the top $30 \%$ of the most deprived areas in Wales. ${ }^{12}$

\section{Statistical analysis}

Analysis was performed using the statistical computing environment R (R Studio open source developing team, V.1.1.456). Baseline characteristics were presented as mean and SD for continuous variables, or numbers and percentages for categorical variables. Differences

\begin{tabular}{|c|c|c|c|c|}
\hline Variable & All $(n=387)$ & $\begin{array}{l}\text { Less deprived } \\
(n=296)\end{array}$ & $\begin{array}{l}\text { More deprived } \\
(n=91)\end{array}$ & $P$ value \\
\hline Age $(m e a n \pm S D)$ & $82.8 \pm 8.3$ & $83.5 \pm 7.9$ & $80.4 \pm 9.3$ & 0.004 \\
\hline Creatinine (mean $\pm S D)$ & $128.4 \pm 96.4$ & $126 \pm 94.3$ & $137 \pm 104.2$ & 0.395 \\
\hline BMI (mean $\pm S D)$ & $27.3 \pm 15.4$ & $27.2 \pm 17.1$ & $27.9 \pm 7.3$ & 0.588 \\
\hline Sex-n male (\%) & $213(54.8)$ & $166(56.1)$ & $47(51.6)$ & 0.457 \\
\hline Marital status—n married (\%) & $199(79.3)$ & $153(83.2)$ & $46(69.7)$ & 0.020 \\
\hline Diabetes-n (\%) & $95(25.7)$ & $75(26.6)$ & $20(23.5)$ & 0.572 \\
\hline Smoking history—n (\%) & $226(64)$ & $173(63.6)$ & $51(64.6)$ & 0.877 \\
\hline Renal disease $-n(\%)$ & $31(8.4)$ & $24(8.5)$ & $7(8.2)$ & 0.936 \\
\hline On dialysis—n (\%) & $13(3.5)$ & $9(3.2)$ & $4(4.7)$ & 0.512 \\
\hline Previous Ml—n (\%) & $106(28.3)$ & $85(29.8)$ & $20(23)$ & 0.215 \\
\hline Lung disease $-n(\%)$ & $120(32.4)$ & $86(30.4)$ & $34(40)$ & 0.097 \\
\hline Previous stroke/TIA—n (\%) & $55(14.7)$ & $43(15.1)$ & $11(12.5)$ & 0.546 \\
\hline Previous cardiac surgery-n (\%) & $100(26.7)$ & $80(28.1)$ & $20(22.7)$ & 0.323 \\
\hline CCS Angina 3/4n (\%) & $56(15.5)$ & $42(15.2)$ & $14(16.7)$ & 0.748 \\
\hline NYHA class III-IV—n (\%) & $345(95)$ & $263(94.9)$ & $81(95.3)$ & 0.897 \\
\hline CSHA frailty moderate/severe— $\mathrm{n}(\%)$ & $88(28.7)$ & $67(28.3)$ & $21(30)$ & 0.779 \\
\hline Poor LV function-n (\%) & $66(19)$ & $43(16.5)$ & $23(26.7)$ & 0.035 \\
\hline Triple vessel coronary disease - $n(\%)$ & $50(14.4)$ & $39(14.9)$ & $11(13.1)$ & 0.685 \\
\hline
\end{tabular}

Data are split by deprivation status. $\mathrm{P}$ values calculated using two sample t-test with unequal variance (continuous variables) or $\mathrm{X}^{2}$ test (categorical variables)

BMI, body mass index; CSHA, Canadian Study of Health and Ageing Frailty Score; LV, left ventricular; MI, myocardial infarction; NYHA, New York Heart Association; TAVI, transcatheter aortic valve implantation; TIA, transient ischemic attack. 


\begin{tabular}{|c|c|c|c|c|}
\hline Variable & $\begin{array}{l}\text { All } \\
(n=387)\end{array}$ & $\begin{array}{l}\text { Less deprived } \\
(\mathrm{n}=296)\end{array}$ & $\begin{array}{l}\text { More deprived } \\
(\mathrm{n}=91)\end{array}$ & $P$ value \\
\hline Femoral approach—n \% & 307 (89.2) & $231(88.5)$ & $74(91.4)$ & 0.470 \\
\hline General anaesthesia—n \% & $131(38.3)$ & $102(39.2)$ & $28(35)$ & 0.496 \\
\hline Complication: $\mathrm{Ml}-\mathrm{n} \%$ & $0(0)$ & $0(0)$ & $0(0)$ & - \\
\hline Complication-death—n \% & $3(0.9)$ & $3(1.2)$ & $0(0)$ & - \\
\hline Complication—tamponade- $\mathrm{n} \%$ & $5(1.5)$ & $5(2)$ & $0(0)$ & - \\
\hline Complication—major apical cannulation-n \% & $0(0)$ & $0(0)$ & $0(0)$ & - \\
\hline Complication—major vascular injury— $\mathrm{n} \%$ & $5(1.5)$ & $4(1.6)$ & $1(1.2)$ & 0.798 \\
\hline Complication—bailout PCl—n \% & $0(0)$ & $0(0)$ & $0(0)$ & - \\
\hline Complication-stroke-n \% & $1(0.3)$ & $1(0.4)$ & $0(0)$ & - \\
\hline Complication—cardiogenic shock- $\mathrm{n} \%$ & $3(0.9)$ & $3(1.2)$ & $0(0)$ & - \\
\hline Emergency valve in valve $-n \%$ & $0(0)$ & $0(0)$ & $0(0)$ & - \\
\hline Device embolisation—n \% & $2(0.6)$ & $2(0.8)$ & $0(0)$ & - \\
\hline Device migration-n \% & $2(0.7)$ & $1(0.5)$ & $1(1.5)$ & 0.415 \\
\hline Gl haemorrhage-n \% & $0(0)$ & $0(0)$ & $0(0)$ & - \\
\hline Tamponade postprocedure-n \% & $1(0.4)$ & $1(0.5)$ & $0(0)$ & - \\
\hline Platelet transfusion- $\mathrm{n} \%$ & $3(1.1)$ & $2(1)$ & $1(1.5)$ & 0.741 \\
\hline Blood transfusion-n $\%$ & $21(7.8)$ & $17(8.5)$ & $3(4.5)$ & 0.279 \\
\hline New dialysis—n (\%) & $30(11.2)$ & $29(14.6)$ & $1(1.5)$ & 0.003 \\
\hline ITU stay $($ mean $\pm S D)$ & $1.8 \pm 2.2$ & $1.9 \pm 2.5$ & $1.6 \pm 1.1$ & 0.087 \\
\hline Total stay $($ mean $\pm S D$ ) & $23.2 \pm 24.5$ & $21.3 \pm 21.1$ & $29.6 \pm 32.7$ & 0.025 \\
\hline In-hospital death & $23(5.9)$ & $17(5.7)$ & $6(6.7)$ & 0.735 \\
\hline
\end{tabular}

Data are split by deprivation status. $\mathrm{P}$ values calculated using two sample t-test with unequal variance (continuous variables) or $\mathrm{X}^{2}$ test (categorical variables)

ITU, intensive treatment unit; MI, myocardial infarction; PCI, percutaneous coronary intervention; TAVI, transcatheter aortic valve implantation.

between the baseline characteristics were analysed using two sample t-test with unequal variance and $\mathrm{X}^{2}$ tests.

Survival analysis was carried out using Kaplan-Meier actuarial outcome analysis to determine difference in 30-day, 1-year and 3-year mortality. HRs for risk of mortality were constructed using Cox proportional HR modelling based on deprivation. Multivariate analysis was carried out to adjust for baseline characteristics using multiple logistic modelling with resulting ORs and 95\% CIs presented as forest plots. Significance was defined at a $\mathrm{p}<0.05$.

All patient information was anonymised and de-identified prior to analysis.

\section{RESULTS}

\section{Patient population and characteristics}

Between 5 November 2009 and 10 June 2018, 387 consecutive patients underwent first-time TAVI at Morriston Cardiac Centre, Swansea. The mean patient follow-up was 578 days. The patient population comprised 213 men $(54.8 \%)$ and mean age at TAVI was 82.8 years (SD 8.3 ) with a range of $47-100$ years. There were 91 patients (23.5\%) deemed as 'more deprived' who underwent TAVI compared with 296 'less deprived'. Patients who were less deprived were more likely to be older $(83.5 \pm 7.9$ vs $80.4 \pm 9.3, \mathrm{p}<0.05)$ and to be married $(83.2 \%$ vs $69.7 \%$, $\mathrm{p}<0.05)$. Baseline characteristics are listed in table 1 .

Conversely 'more deprived' patients were more likely to have a longer stay in hospital as compared with patients in the 'less deprived group' (29.6 \pm 32.7 days vs $21.3 \pm 21.1$ days, $\mathrm{p}<0.05)$. Procedural and in-hospital outcome variables are shown in table 2.

\section{Overall survival based on deprivation status}

Kaplan-Meier survival analysis showed that there was no significant difference in survival between deprivation groups at 30-day, 1-year and 3-year end points (figure 1A-C). Statistical analysis using a Cox proportional hazards analysis and log-rank tests showed no increased hazards for mortality (figure 1D).

\section{Multivariate analysis of baseline characteristics}

Forest plot of multiple logistic regression modelling of mortality, adjusted for age, sex, marital status, diabetes, smoking status, lung disease and left ventricular function can be seen in figure 2. This was carried out at 30-day, 1 -year and 3-year endpoints. It shows that even after adjusting for these variables, deprivation status does not 


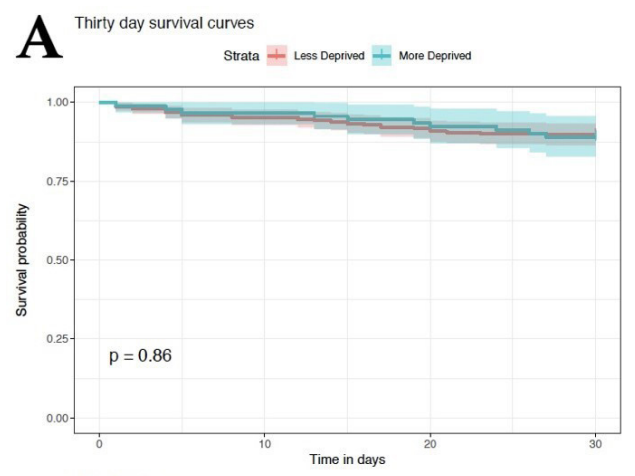

B One year survival curves
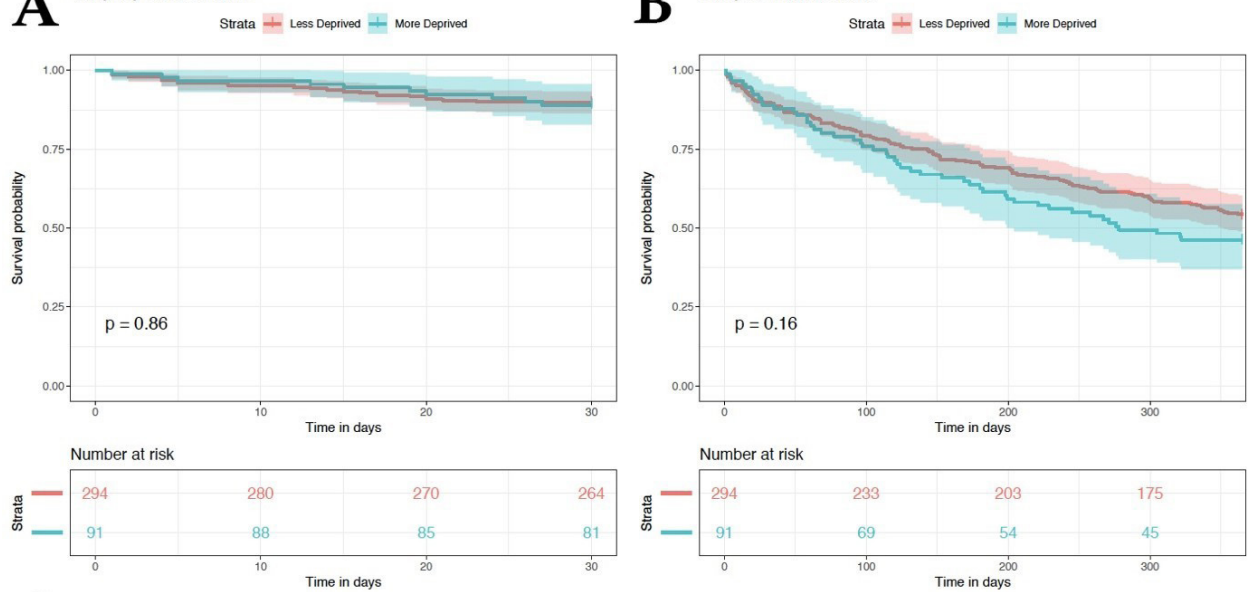

Chree year survival curves

D
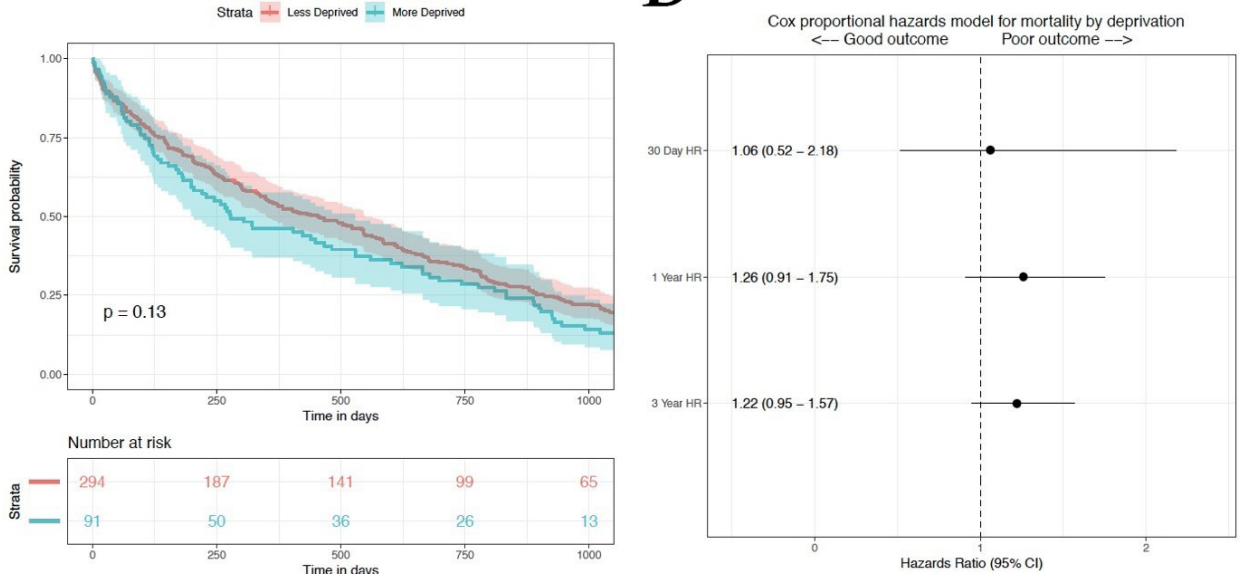

Figure 1 Survival analysis of patients who underwent TAVI stratified by deprivation status. There were no statistically significant differences in survival between groups at 30 days (A), 1-year (B) or 3-year (C) as determined by log-rank testing. Cox proportional hazards are displayed in (D) confirming no statistical significance by $95 \% \mathrm{Cls}$. TAVI, transcatheter aortic valve implantation.

increase short-term or intermediate-term mortality in patients undergoing TAVI procedures.

\section{DISCUSSION}

This study is the first to date to investigate associations between deprivation and outcomes in patients undergoing TAVI. We found that socioeconomic status had no impact on survival rate up to 3 years after TAVI. However, low socioeconomic status was independently associated with a longer stay in hospital post-TAVI. These findings are of importance for two reasons. First, given the association between socioeconomic deprivation and
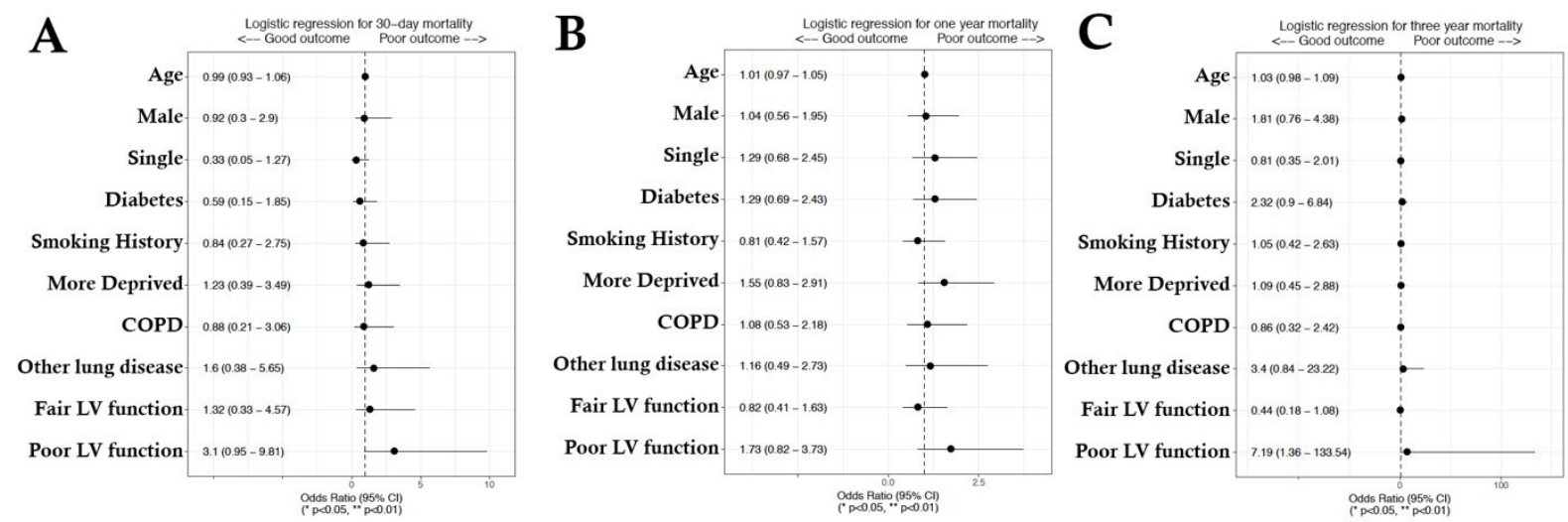

Figure 2 Forest plot of multiple logistic regression modelling of mortality, adjusted for age, sex, marital status, diabetes, smoking status, lung disease and LV function. COPD, chronic obstructive pulmonary disease; LV, left ventricular. 
the increased prevalence of heart valve disease ${ }^{9}$ and second, the increasing volume of TAVI implants that are likely to occur as a result of the recently published lowrisk trials of TAVI versus conventional surgery. ${ }^{34}$

The design of our study built on previous evidence that factors such as coronary artery disease (CAD), left ventricular dysfunction and frailty varied in their prevalence according to deprivation status. However, we found that none of these factors influenced mortality following TAVI, in our 'more deprived' study population. The influence of coexisting $\mathrm{CAD}$ has been reported to have a detrimental effect on survival rate if patients are not revascularised in relation to surgical valve replacement. ${ }^{13} 14$ According to The Euro Heart Survey on Valvular Heart Disease, fewer than $25 \%$ patients undergoing single aortic or mitral valve replacement have additional coronary artery bypass graft $(\mathrm{CABG}) .{ }^{15}$ As ischaemic heart disease generally has a higher prevalence in a disadvantaged population, a higher rate of coexisting CAD would be expected among valve disease patients from a disadvantaged background, and therefore, a higher operative mortality rate in this group. ${ }^{16-18}$ Either this was not the case, and we found no difference in angiographically defined three vessel CAD between the deprivation groups in our population, or coexisting CAD did not play a major role for the operative survival after percutaneous valve replacement in our UQQQcohort, irrespective of socioeconomic level.

Being domiciled in a deprived community has been reported a risk factor for outcome 3 years after coronary bypass grafting ${ }^{19}$ but no Welsh study was available for comparison. There are other several possible reasons for a poorer long-term outcome for disadvantaged patients after major cardiac procedures. Low socioeconomic status has been associated with lower rates of exercise and conversely higher rates of smoking, alcohol intake and unemployment rates. ${ }^{19}{ }^{20}$ Also higher lipid levels, a higher prevalence of obesity and diabetes, and hypertension among the socially most deprived may all contribute to a higher long-term mortality rate ${ }^{18-20}$ Furthermore, several studies have shown that economically disadvantaged subjects are less likely to benefit from evidencebased advances in medical care or undergo invasive cardiac evaluation and revascularisation than their less deprived counterparts. ${ }^{131521}$ It has been suggested that more deprived people may not be able to afford prescription drugs. ${ }^{15}$ Furthermore, diseases other than CAD (eg, cancer, infections and hip fractures) have been reported more frequently among patients from socially deprived areas and may contribute to a poorer long-term outcome. ${ }^{22} 23$

\section{Limitations}

This study has a number of limitations. One potential limitation of the study is that our small sample size, so the results are only generalisable to high-risk TAVI patients in a UK population. As a result of the study design and the inherent nature of patients, a number of the independent variables investigated were potentially interdependent and an increase in one variable inadvertently leads to an increase in another.

Multivariable logistic regression was used in an attempt to address this issue of collinearity. It is also possible that a confounding variable that influences the results was not considered in the data collection or analysis. It could, therefore, be suggested that the discovered association between social deprivation and prolonged length of stay is the result of both risk factor and outcome being related to common underlying unmeasured pathologies. Also, our database did not record cause of death. In prognostic clinical research, however, this is difficult to overcome due to the nature of the study population, and therefore, the results of the study should be interpreted with this in mind.

Another study limitation involves the use of the WIMD 2014 codes and the income domain indicator as the measure of social deprivation. This is a measure of area rather than individual deprivation and it is important to consider therefore that not everyone living in a deprived area is deprived, and that not all deprived people live in deprived areas. It should also be highlighted subsequent analysis of components of a composite outcome measure could lead to erroneous conclusions due to multiple testing. This should be taken into account when considering the results of this study.

\section{CONCLUSIONS}

This is the first study in which socioeconomic deprivation has been investigated as a risk factor for mortality following TAVI. The results of the study indicate that a disadvantaged social background did not impact on survival in a high-risk group of patients with symptomatic severe AS undergoing TAVI. Social deprivation, however, was found to be a risk factor for prolonged length of in-hospital stay and may, therefore, influence procedural planning and discharge strategies.

Contributors KM and DS developed the idea and designed the project. All authors participated in collecting and analysing the data. KM generated the first draft of the paper. KM, MBP and DS reviewed the draft and amended it. All authors approved the final version.

Funding The authors have not declared a specific grant for this research from any funding agency in the public, commercial or not-for-profit sectors.

Competing interests None declared.

Patient consent for publication Not required.

Ethics approval The South West Wales Research and Ethics Committee confirmed that ethical approval was not required for this study and also waived the need to obtain written informed consent from the patients.

Provenance and peer review Not commissioned; externally peer reviewed.

Data availability statement All data relevant to the study are included in the article or uploaded as online supplementary information.

Open access This is an open access article distributed in accordance with the Creative Commons Attribution Non Commercial (CC BY-NC 4.0) license, which permits others to distribute, remix, adapt, build upon this work non-commercially, and license their derivative works on different terms, provided the original work is properly cited, appropriate credit is given, any changes made indicated, and the use is non-commercial. See: http://creativecommons.org/licenses/by-nc/4.0/. 
ORCID iDs

Kevin Mohee http://orcid.org/0000-0002-7409-7197

Majd B Protty http://orcid.org/0000-0001-8992-9120

\section{REFERENCES}

1 Thaden JJ, Nkomo VT, Enriquez-Sarano M. The global burden of aortic stenosis. Prog Cardiovasc Dis 2014;56:565-71.

2 Perrin N, Frei A, Noble S. Transcatheter aortic valve implantation: update in 2018. Eur J Intern Med 2018;55:12-19.

3 Mack MJ, Leon MB, Thourani VH, et al. Partner 3 Investigators. transcatheter aortic-valve replacement with a Balloon-Expandable valve in low-risk patients. N Engl J Med 2019.

4 Popma JJ, Deeb GM, Yakubov SJ, et al. Evolut low risk tria Investigators. transcatheter aortic-valve replacement with a selfexpanding valve in low-risk patients. N Engl J Med 2019.

5 Romeri E, Baker A, Griffiths C. Mortality by deprivation and cause of death in England and Wales, 1999-2003

6 Hacking JM, Muller S, Buchan IE. Trends in mortality from 1965 to 2008 across the English north-south divide: comparative observational study. BMJ 2011;342:d508.

7 McCartney D, Scarborough P, Webster P. Trends in social inequalities for premature coronary heart disease mortality in Great Britain, 1994-2008: a time trend ecological study. Br Med J Open 2012;2.

8 Taylor FC, Ascione R, Rees K. Socioeconomic deprivation is a predictor of poor postoperative cardiovascular outcomes in patients undergoing coronary artery bypass grafting. Heart 2003;89:1062-6.

9 d'Arcy JL, Coffey S, Loudon MA, et al. Large-Scale community echocardiographic screening reveals a major burden of undiagnosed valvular heart disease in older people: the OxVALVE population cohort study. Eur Heart J 2016;37:3515-22.

10 Welsh Government Knowledge and Analytical Services. Welsh index of multiple deprivation, 2014. Available: https:/gov.wales/ sites/default/files/statistics-and-research/2019-04/welsh-index-ofmultiple-deprivation-2014-revised.pdf [Accessed 4 Apr 2019].

11 Battle $\mathrm{C}$, Hutchings $\mathrm{H}$, Bouamra $\mathrm{O}$, et al. Social deprivation and adult blunt chest trauma: a retrospective study. J Intensive Care Soc 2015;16:18-23.

12 Research and information unit, City and Council of Swansea. Welsh index of multiple deprivation, 2011. Available: http://www.swansea.
gov.uk/media/pdf/o/n/WIMD 2011 R I Briefing Note v2 Oct-11. pdf [Accessed 5 Sep 2014].

13 Lund O, Nielsen TT, Pilegaard HK, et al. The influence of coronary artery disease and bypass grafting on early and late survival after valve replacement for aortic stenosis. J Thorac Cardiovasc Surg 1990;100:327-37.

14 Mullany CJ, Elveback LR, Frye RL, et al. Coronary artery disease and its management: influence on survival in patients undergoing aortic valve replacement. J Am Coll Cardiol 1987;10:66-72.

15 Rao SV, Kaul P, Newby LK, et al. Poverty, process of care, and outcome in acute coronary syndromes. J Am Coll Cardiol 2003;41:1948-54.

16 Alter DA, Naylor CD, Austin P, et al. Effects of socioeconomic status on access to invasive cardiac procedures and on mortality after acute myocardial infarction. N Engl J Med 1999;341:1359-67.

17 Morrison C, Woodward M, Leslie W, et al. Effect of socioeconomic group on incidence of, management of, and survival after myocardia infarction and coronary death: analysis of community coronary event register. BMJ 1997;314:541-6.

18 Matata BM, Shaw M, Grayson AD, et al. The impact of social deprivation on coronary revascularisation treatment outcomes within the National health service in England and Wales. Eur J Prev Cardiol 2016;23:316-27.

19 Barnard J, Grant SW, Hickey GL, et al. Is social deprivation an independent predictor of outcomes following cardiac surgery? An analysis of 240221 patients from a national registry. BMJ Open 2015;5:e008287.

20 Rathore SS, Berger AK, Weinfurt KP, et al. Race, sex, poverty, and the medical treatment of acute myocardial infarction in the elderly. Circulation 2000;102:642-8.

21 Salomaa Vet al. Relation of socioeconomic position to the case fatality, prognosis and treatment of myocardial infarction events; the FINMONICA MI register study. J Epidemiol Commun Health 2001;55:475-82.

22 Heller RF, McElduff P, Edwards R. Impact of upward social mobility on population mortality: analysis with routine data. BMJ 2002;325:134-6.

23 Thorne K, Johansen A, Akbari A, et al. The impact of social deprivation on mortality following hip fracture in England and Wales: a record linkage study. Osteoporos Int 2016;27:2727-37. 